\title{
Student perceptions of working collaboratively during undergraduate study to produce a knowledge repository based on wiki technology
}

\section{Zeller Pimlott \& Tricia Tikasingh}

School of Human and Social Sciences, University of West London, London, UK

Corresponding author: Zeller Pimlott, University of West London, Paragon House 4th Floor, Boston Manor Road, Brentford, TW8 9GA. E-mail: Zeller.Pimlott@uwl.ac.uk. ORCID: https://orcid.org/0000-0002-5046-6656

Zeller Pimlott is a senior lecturer at the University of West London. Her previous research was in nutrition and her current research is on ways to enhance student learning.

Tricia Tikasingh is course leader of the BSc in Nutritional Therapy at the University of West London and quality lead for the School of Human and Social Sciences. She has a background in medicinal plant research in the Caribbean. Her current interests include distance-learning student engagement.

Word Count: 5000 


\title{
Student perceptions of working collaboratively during undergraduate study to produce a knowledge repository based on wiki technology
}

\author{
This study reports on student perceptions of working collaboratively to produce a \\ knowledge repository. The repository was a novel use of a wiki in which a database of \\ information was created progressively from student contributions over a period of three \\ and a half years. The views of students in their final year of study were collected \\ through a focus group and thematic analysis was conducted. The findings include \\ student perceptions of working collaboratively and their views of the potential \\ usefulness of the content for study and professional life. It was found that students \\ prefer content that has been enriched with the personal research, ideas or experiences of \\ the group of students, as it contains 'added value' over information readily available on \\ the internet. Accuracy and currency of the content is a concern for students. \\ Implications for educators considering using knowledge repositories are discussed and \\ improvements for this implementation are identified.
}

Keywords: knowledge repository; wiki; undergraduate education; student perceptions; focus group; collaborative learning

\section{Introduction}

In its simplest form, a wiki is a set of online pages that can be added to, viewed and edited by anyone within the group of users, providing a suitable environment for collaboration to produce and share content (Godwin-Jones, 2003). In the last fifteen years, wikis have been adopted increasingly in the field of education as tools for collaborative learning ( $\mathrm{Li}, 2018$; Rasmussen, Lewis \& White, 2013; Trocky \& Buckley, 2016). As a web 2.0 technology, the wiki supports active participation and is compatible with constructivist learning practices (Cole, 2009; Karasavvidis, 2010; Su \& Beaumont, 2010; Trocky \& Buckley, 2016). Research studies have shown that wikis can be used effectively to enhance students' collaborative work in higher education contexts ( Altanopoulou, Tselios, Katsanos, Georgoutsou, \& Panagiotaki, 2015; Cho \& Lim, 2017; Chu et al., 2017; de Arriba, 2017; Trocky \& Buckley, 2016). 
One of the possible uses to which wiki technology has been put is in the creation of electronic repositories of knowledge, an example of which is the online encyclopaedia 'Wikipedia'. Wiki-based repositories of knowledge have been widely applied as tools for the management of organisational knowledge (Bibbo, Michelich, Sprehe, \& Lee, 2012). In education, the number of studies reporting the use of a wiki to create a knowledge repository is relatively small; most wiki studies involve collaborative projects, often involving production of a piece of text, with the aim of enhancing learning and/or students' writing skills (Trocky \& Buckley, 2016).

Many of the examples of knowledge repositories in education come from the field of medical education (Rasmussen et al., 2013). Kohli and Bradshaw (2011) and Crotty, Mostaghimi and Reynolds (2012) conducted studies on the use of wikis by resident doctors in the USA. The dual aims of these wikis were centralising information and empowering users to maintain a high quality of information by collaborative authorship. Educational content was only one part of the information in these repositories and the most frequently viewed items were administrative resources.

Donne and Lin (2013) report the creation of a knowledge repository to provide online support for newly graduated special education teachers. Contributors included current students, new graduates, and researchers. The content included a wide range of information: course and professional development information, a resource database and students' work experiences.

In contrast to the repositories described above, Elliott, Koerner, Heasley and Kamal (2012) describe a study in which the content of the repository was solely educational. This repository was built up progressively over one semester of a doctor of pharmacy programme with the aim of increasing students' knowledge of medication in pregnancy and paediatrics and also skills in lifelong learning. The repository was highly regarded by students and 
continued to be used by $75 \%$ of them after the course was completed. Another knowledge repository in which the majority of the material is educational is that produced by medical students of the University of Minnesota (Thompson, Schulz \& Adam, 2011). This repository developed from a paper-based lecture note sharing system. All students at the medical school can view and edit class notes on this wiki, which serves as an online textbook. After four years, the repository had 1.2 million page views.

Qualitative data on student perceptions of collaborative work on wikis has been obtained through focus groups or interviews (Chu et al., 2017; Cole, 2009; Karasavvidis, 2010; O'Bannon, Lubke \& Britt, 2013; Su \& Beaumont, 2010) and additional data has come from open-ended questions in surveys (Kear, Donelan \& Williams, 2014; Moon-Heum \& Lim, 2017; Sharp \& Whaley, 2018; Witney \& Smallbone, 2011). With regards to students' perceptions of using knowledge repository wikis specifically, less data is available due to the relatively small number of educational studies involving a knowledge repository; some quantitative data about perceived usefulness has been obtained from surveys (Crotty et al., 2012; Elliott et al., 2012).

This paper reports on the findings of a focus group held with the aim of exploring students' perceptions of contributing to and using a wiki-based knowledge repository on an undergraduate degree programme. A further aim was to identify ways in which the repository could be improved to better support learning. This repository is a novel use of a wiki in which the knowledge base is created progressively over three and a half years of the programme, with content being added during each of the individual courses, so that the resulting information is spread over the curriculum as a whole. This study contributes to the literature by providing rich qualitative data on student perceptions of contributing to and using a wikibased knowledge repository. In addition, findings that are of particular relevance to a 
knowledge repository wiki are discussed with reflection on implications for other educators considering using a wiki in this way.

\section{Method}

\section{Context}

This study concerns students on an undergraduate degree programme in nutritional therapy at a UK university. The degree is part-time distance-learning and takes five years to complete, with three weeks of attendance in the final year for clinical training and assessment. Most students intend to start a private practice in nutritional therapy on graduating. Nutritional therapists give advice to clients about diet, nutritional supplements and lifestyle changes to support health and wellbeing. The rationale for the knowledge repository was to increase students' readiness for practice by encouraging them to engage with professional resources and by facilitating the production of an online resource of clinically-focused information that would be helpful for the clinical assessment and later professional life. As the degree is distance-learning, a further rationale was to increase student interaction and provide the opportunities to share ideas that are available to students who attend classes together.

Each cohort of students has its own repository, which cannot be seen by students of other cohorts. The repository is empty initially. As students progress through a course, a page is created by the tutor for each task, which may be a formative assessment or a learning activity. An example of a task is 'Suggest a healthy snack of low glycaemic index, giving a rationale for each ingredient.' Students edit the page to add their own contribution below those already submitted, labelled with their name. The addition of extra information or comments to other students' contributions is encouraged. Students do not receive marks for their contributions, but they benefit from the use of the collective information in the knowledge repository and the individual and general feedback given by the tutor. The 
educational benefits of the repository will be measured by students' readiness for practice as demonstrated during the final year clinical assessment. The wiki used is part of the Blackboard learning management system that the students use for their study.

\section{Participants}

Eight students on a part-time distance-learning course in nutritional therapy at a UK university participated in the study (one male and seven females). The participants were in their final year of study and had used the wiki for three and a half years. Participation was voluntary but all members of this cohort chose to take part. The participants are referred to as P1 to P8 in the text. Ethical approval was obtained from the ethics committee of the School of Human and Social Sciences at the University of West London.

\section{Data collection}

Data was collected through a focus group discussion. The facilitator was a tutor with no teaching responsibilities with this cohort for the remainder of the programme. The following question was posed to start the discussion: 'What has been your experience of using the wiki while preparing for the clinical practice assessment?' For the first forty five minutes the conversation was allowed to flow with minimal intervention so as to elicit discussion on issues of importance for the participants. Prompts were prepared but were not needed. In the second part of the session a ranking activity was undertaken to encourage the group to come to a consensus and to provide some triangulation for the findings from the first part of the session (Colucci, 2007). The discussion continued for a further thirty minutes. The statements to be ranked were derived from the authors' identification of potential issues based on their experience as tutors on the programme (see Appendix 1 for the statements). 


\section{Data analysis}

The focus group discussion was audio recorded and transcribed. Themes were identified and analysed using thematic analysis following an inductive approach (Braun \& Clarke, 2006). The transcript was independently analysed by the two authors and the identified themes and sub-themes compared and agreed upon.

\section{Findings}

Three main themes were identified.

\section{Theme 1 - usefulness of the knowledge repository content for study and future professional life}

Students agreed that the best type of content is that which has been enriched with the personal research, ideas, and experiences of members of the group. This material is highly valued as '... it belongs to us, it belongs to our group' (P8), and also because it is not readily available on the internet and so provides a rationale for using the repository. Students also value such material as they feel it can be trusted:

You have done a bit of research and I would think, that is incredible, I know that you have researched it properly and I would use that (P7).

...because we trust that everything that everyone has written is to the same principle of being evidence-based and checked (P8).

A frequently mentioned point was a preference for content in the form of information sheets that can be given to clients when in practice. Students would each contribute a different sheet, for example 'Food sources of iron', 'Food sources of calcium' etc, so the workload of producing practice resources could be shared across the group. 
Accuracy and currency of the content was an issue of concern for students. The possibility that contributions made early in their studies may no longer be up-to-date, or may have been done to a lower standard, prevented them from using the content. One of the most frequently mentioned points in the discussion was a desire for tutors to check the content, although there was some acknowledgement that this may not be feasible.

Students commented on how the usefulness of the repository could be enhanced with changes to the overall structure. They suggested an organisation based on topic, with a structure similar to that of the programme and also that this structure should be present from the beginning, rather than the repository being 'a blank canvas':

... some sort of structure of headings and topics and where the course will be going overall ... to see that through the duration you are filling up this sort of, like, empty journal of knowledge (P8).

\section{Theme 2 : working collaboratively}

The most frequently discussed issue was students' lack of confidence in their contributions, resulting in reluctance to let others see their work. In the ranking activity, 'Worries about the quality of my contribution' was placed second in the list of worst things about using the wiki. One student commented:

I don't like sharing my work because I am not confident in what I am putting up there and I don't want to put something wrong which, you know, which would be awkward or a problem (P4).

Students frequently waited for someone else to post their contribution first before posting their own. Another consequence was that they were hindered from adding to, or commenting on, the work of other students. More confidence was felt by students in cases where a tutor had written and posted an example of a contribution to show what was expected: 
I think that when I know how to pitch it, I feel more relaxed and more confident in contributing (P3).

Students felt that they would be more confident to make a contribution if it was checked by a tutor:

I'd just like some confirmation from you [a tutor] that it is either wrong, and this is the right way, or that I have got it right, it would make me feel more confident (P4).

Students agreed that they would have had confidence to post earlier in the course if they had met each other at the start of the programme. After meeting in the final year, students were more willing to contribute:

I think that because before we didn't see each other as well, or as much, or we didn't put a name to the face and now we are more connected so that it is easier (P6).

A few students felt guilty if using other students' work without having contributed. Some other limitations of working collaboratively expressed in the group were the need to do the research oneself in order for it to 'stick', and the extra study time required to read other students' contributions.

Sharing of the workload was regarded as a major advantage of working collaboratively; as one student (P6) commented '... we share the activities so that we don't have to do everything all by ourselves'. An example is that each student did research on a different micronutrient so that everyone had access to the information for all the micronutrients but only had to research one themselves. 'Enabled the group to share the workload' was placed in second place in the list of the best things about using the wiki. 
Another advantage of working collaboratively that was mentioned frequently by students was the opportunity to learn from others. 'Interesting to see other students' ideas' was placed in first place in the list of best things about using the wiki. Some comments were:

I may have thought down this road, this angle, or whatever and suddenly someone's brought in something else and I am like, 'Wow, I didn't even think about that', and then it makes me go off and perhaps do a little bit more reading on that area (P7).

It's definitely good to realise that there are all different viewpoints and angles, ...you maybe have a fixed idea about this but then when you read somebody else's reading, 'Ah yes, that's right.' (P5).

\section{Theme 3 - using the knowledge repository as part of the programme}

Students agreed that using the knowledge repository had helped them to interact; one student (P7) commented 'I think it is great to just get us all connected'.

The issue that was brought up most frequently was whether all tasks should be designated as formative assessments; at present, some are informal activities. Students felt that if a task was not an assessment then many would not contribute:

I think it becomes very much that only people who perhaps have time to spare might be contributing (P2).

I think for the wiki to work it has to be tied in to some formal formative work, you know, otherwise if it's kind of left to your own devices, because people don't have time or whatever, I don't think it is going to work (P7).

There was a strong consensus on this issue. In the list of worst things about using the wiki, 'Extra work that doesn't count towards assessment' was placed in first place. 
Another topic discussed was whether students had added information independently, outside of specific activities, as suggested at the start of the project. There was a strong consensus that they had not done so. One student commented:

I think we could have used it, maximised the use of it, by sharing more on there, you know, and used it as a proper sharing resource (P7).

A reluctance to spend time on work that was not part of a formative assessment was relevant to this issue too, with one student explaining:

I struggle to just do the workload itself, you know, rather than having to dip into a wiki and add information and stuff because I work full-time (P1).

\section{Discussion}

\section{Student perceptions of working collaboratively on a wiki}

Students reported that using the repository encouraged interaction and enabled them to share the workload and learn from other students. In other studies students have reported that a wiki was effective in improving collaboration (Benson, Brack \& Samarwickrema, 2012; Chu et al., 2017; Cilliers, 2017; Kear et al., 2014; O'Bannon et al., 2013; Sharp \& Whaley, 2018). The most frequently mentioned issue in this study was students having a lack of confidence in their work and being reluctant to post as a result. Other researchers (Cilliers, 2017; Cole, 2009; Su and Beaumont, 2010) have reported that some students express discomfort with fellow students seeing their work. In a study by Cole (2009) $14 \%$ of questionnaire respondents cited the reason for not posting to the class wiki as doubts about the quality of their contribution. In the current study students reported feeling more confident in posting when the tutor had put up an example contribution. Cole (2009) reflects that self confidence issues may be mitigated by greater instructional scaffolding and this was supported by the 
findings of Cho and Lim (2017). Providing more example contributions is a possible improvement for the current repository project.

A lack of confidence contributed also to students' reluctance to add to, or comment on, the work of other students. This reluctance has been found in other studies, with reasons given that it was inappropriate to amend others' ideas, that it would suggest that other students' work was lacking, and that it may cause annoyance to fellow students (Cilliers, 2017; Karasavvidis, 2010; O'Bannon et al., 2013). In the study by Su and Beaumont (2010), the proportion of students who expressed confidence in giving feedback to peers improved from $39 \%$ to $64 \%$ within a three month period. The study's authors suggest that this was due to the experience of using the wiki and also the opportunity for students to model their feedback on that given by tutors to other students on the wiki. In the study by Kear et al. (2014), $78 \%$ of students indicated that they were comfortable about group members editing each other's contribution. In the studies by Kear et al. (2014) and Su and Beaumont (2010), peer review tasks were a requirement of the assessment; possibly this helped to increase acceptance of peer feedback within the student group. Inclusion of peer review tasks may be helpful in the current project.

Students felt more confident to post after they had met each other and some suggested it would be helpful to meet earlier in the programme. O'Bannon et al. (2013) found that lack of face-to-face contact was one of the three factors that most inhibited wiki collaboration, with some students reporting discomfort when communicating online with someone they did not know. In a study by Benson et al. (2012) in which teachers collaborated on a wiki-based task in a staff development workshop, a perceived limitation of using the wiki was difficulty in collaborating with unknown people. Students in studies conducted by Cho and Lim (2017) and Moon-Heum and Lim (2017) valued opportunities for face-to-face communication. In the current study, as students make individual contributions rather than writing collaboratively, 
interaction is limited. In other studies (Kear et al., 2014; Su \& Beaumont, 2010) students had the opportunity to discuss the wiki task with other students on an online space separate from the wiki page. Kear et al. (2014) report that $97 \%$ of students found it was useful to have a forum in addition to the wiki. Providing a discussion forum for each task in the current project may encourage students to interact and get to know each other, thereby gaining confidence in posting.

There was a strong consensus that wiki tasks should be assessments, in particular so that all students contribute. Cole (2009) found that for $29 \%$ of students deadlines from other courses were the reason for not contributing to the class wiki and reflects that students will tend to prioritise assessed coursework and paid non-academic work over non-assessed wiki contributions. Based on a review of the literature and their research experience, Rasmussen et al. (2013) conclude that a low rate of participation will be achieved if a wiki contribution is not assessed.

\section{Findings that are particularly relevant to knowledge repositories and implications for other educators}

Type of content

Students felt that the type of content in the knowledge repository should be different from that readily available on the internet in order to provide a rationale for using the repository. The students favoured information enriched with their personal research, ideas or experiences, as this has 'added value' over that available on the internet. An example is the task mentioned earlier where students were asked to contribute an idea for a healthy snack. In this case basic nutritional information available on the internet was enriched with students' personal food and culinary experience and additional research. Another issue that was 
mentioned on several occasions was that students prefer content in the form of information sheets that would be suitable for giving to clients as this would save them time when setting up a practice.

\section{Accuracy and currency of content}

This is an important consideration for any project in which students build up a repository of knowledge for later use. In this study, students reported that concern about this issue had prevented them from using the information. One of the most frequently mentioned points in the discussion was a desire for tutors to check the content of contributions for accuracy. In the context of the current study, making all contributions assessments would help student confidence as then tutor feedback would be given and inaccuracies could be amended. In the postgraduate medical repository described by Crotty et al. (2012) editors are designated for each section and are automatically notified of edits so they can conduct a review. In the study by Kohli and Bradshaw (2011), designated individuals conduct a daily surveillance. For any repository in which a knowledge base is built up over a significant period of time, currency of the information is a major issue. In the study by Elliott et al. (2012), after course completion it became the students' responsibility to ensure that any information they accessed was up-todate. In the study by Crotty et al. (2012) section editors have responsibility for keeping content current. For the current study, choosing content less likely to become out-of-date within a short timescale may help to avoid problems.

\section{Structure of the repository}

Students in this study suggested that it would be beneficial if the repository had a structure similar to that of the programme as a whole, with an 'empty' repository being present from the start of the course with topic headings, as a form of sign-posting of what was to come. 


\section{Conclusion}

The focus group discussion produced some rich qualitative data capturing students' perceptions of using and contributing to a knowledge repository over a period of three and a half years. A limitation of this study is that it is based on a small group of distance-learning students. Lessons have been learned from this first implementation of a knowledge repository:

\section{Lessons learned - ideas for improvements}

(1) Include example contributions for all tasks.

(2) Introduce earlier opportunities for students to meet.

(3) Provide a discussion forum for each task separate from the contribution area.

(4) Make each task an assessment.

(5) Include peer review tasks.

(6) Focus on content based on students' personal research, ideas, and experiences.

(7) Include more tasks in which students produce client information sheets.

(8) Provide a repository structure with topic headings from the beginning of the programme.

(9) Include some individual interviews and quantitative research in future studies.

Acknowledgements

We would like to thank our colleagues in the School of Human and Social Sciences for their help and the students who took part in the discussion with such enthusiasm.

\section{References}

Altanopoulou, P., Tselios, N., Katsanos, C., Georgoutsou, M., \& Panagiotaki, M.A. (2015). Wiki-mediated activities in higher education: evidence-based analysis of learning effectiveness across three studies. Educational Technology \& Society, 18(4), 511-522. 
Benson, R., Brack, C., \& Samarwickrema, G. (2012). Teaching with wikis: improving staff development through action research. Research in Learning Technology, 20(2), 16149.

Bibbo, D., Michelich, J., Sprehe, E., \& Lee, Y. (2012). Employing wiki for knowledge management as a collaborative information repository: an NBC universal case. Journal of Information Technology Teaching Cases, 2(1), 17-28.

Braun, V., \& Clarke, V. (2006). Using thematic analysis in psychology. Qualitative Research in Psychology, 3(2), 77-101.

Cho, M., \& Lim, S. (2017). Using regulation activities to improve undergraduate collaborative writing on wikis. Innovations in Education and Teaching International, 54(1), 53-61.

Chu, S.K.W., Zhang, Y., Chen, K., Chan, C.K., Lee, C.W.Y., Zou, E., \& Lau, W. (2017). The effectiveness of wikis for project-based learning in different disciplines in higher education. Internet and Higher Education, 33, 49-60.

Cilliers, L. (2017). Wiki acceptance by university students to improve collaboration in higher education. Innovations in Education and Teaching International, 54(5), 485-493.

Cole, M. (2009). Using wiki technology to support student engagement: Lessons from the trenches. Computers \& Education, 52(1), 141-146.

Colucci, E. (2007). 'Focus groups can be fun': the use of activity-oriented questions in focus group discussions. Qualitative Health Research, 17(10), 1422-1433.

Crotty, B.H., Mostaghimi, A., \& Reynolds, E.E. (2012). Adoption of a wiki within a large internal medicine residency program: a 3-year experience. Journal of the American Medical Informatics Association, 19(4), 621-625.

de Arriba, R. (2017). Participation and collaborative learning in large class sizes: wiki, can you help me? Innovations in Education and Teaching International, 54(4), 364-373.

Donne, V., \& Lin, F. (2013). Special education teacher induction: the wiki way. The Clearing House, 86(2), 43-47.

Elliott, J.P., Koerner, P.H., Heasley, J., \& Kamal, K.M. (2012). The impact of elective activelearning courses in pregnancy/lactation and pediatric pharmacotherapy. American Journal of Pharmaceutical Education, 76(2), article 26.

Godwin-Jones, R. (2003). Emerging technologies. Blogs and wikis: environments for on-line collaboration. Language Learning \& Technology, 7(2), 12-16. 
Karasavvidis, I. (2010). Wiki uses in higher education: exploring barriers to successful implementation. Interactive Learning Environments, 18(3), 219-231.

Kear, K., Donelan, H., \& Williams, J. (2014). Using wikis for online group projects: student and tutor perspectives. The International Review of Research in Open and Distributed Learning, 15(4), 70-90.

Kohli, M.D., \& Bradshaw, J.K. (2011). What is a wiki, and how can it be used in resident education? Journal of Digital Imaging, 24(1), 170-175.

Li, M. (2018). Computer-mediated collaborative writing in L2 contexts: an analysis of empirical research. Computer Assisted Language Learning, 31(8), 882-904.

Moon-Heum, C., \& Lim, S. (2017). Using regulation activities to improve undergraduate collaborative writing on wikis. Innovations in Education and Teaching International, 54(1), 53-61.

O'Bannon, B., Lubke, J., \& Britt, V. (2013). 'You still need that face-to-face communication': drawing implications from preservice teachers' perceptions of wikis as a collaborative tool. Technology, Pedagogy and Education, 22(2), 135-152.

Rasmussen, A., Lewis, M., \& White, J. (2013). The application of wiki technology in medical education. Medical Teacher, 35(2), 109-114.

Sharp, L.A., \& Whaley, B. (2018). Wikis as online collaborative learning experiences: "A Different Kind of Brainstorming". Adult Learning, 29(3), 83-93.

Su, F., \& Beaumont, C. (2010). Evaluating the use of a wiki for collaborative learning. Innovations in Education and Teaching International, 47(4), 417-431.

Thompson, C.L., Schulz, W.L., \& Adam, T.J. (2011). A Student Authored Online Medical Education Textbook: Editing Patterns and Content Evaluation of a Medical Student Wiki. AMIA Annual Symposium Proceedings 2011, 1392-1401.

Trocky, N.M., \& Buckley, K.M. (2016). Evaluating the impact of wikis on student learning outcomes: an integrative review. Journal of Professional Nursing, 32(5), 364-376.

Witney, D., \& Smallbone, T. (2011). Wiki work: can using wikis enhance student collaboration for group assignment tasks? Innovations in Education and Teaching International, 48(1), 101-110. 


\section{Appendix 1}

\section{Statements for the ranking activity}

What was the best thing about using the wiki? Rank the following statements in order, putting first the statement that most closely matches your experience:

- Enabled the group to share the workload.

- Encouraged interaction in the group.

- Made me think about clinical practice earlier in the course.

- Built a repository of knowledge to help with clinical practice assessment.

- Interesting to see other students' ideas.

And what was the worst thing about using the wiki?

- Extra work that doesn't count towards assessment

- Having to share my work

- Difficult to access or use

- Worries about quality of my contribution

- Cannot see any value in it 